\title{
13th International Conference on the Chemistry of Antibiotics and Other Bioactive Compounds (ICCA-13)
}

\author{
Herbert A Kirst \\ The Journal of Antibiotics (2014) 67, 269-272; doi:10.1038/ja.2013.131; published online 4 December 2013
}

ICCA-13 (13th International Conference on the Chemistry of Antibiotics and Other Bioactive Compounds) was very well-organized by its chairman, Prof. Toshiaki Sunazuka (Kitasato University) with the aid of Emeritus Prof. Satoshi Ōmura (Kitasato University) and their colleagues on the organizing committees. The conference was held on 24-27 September 2013, at the Fuji-View Hotel, Yamanashi Prefecture, Japan. Although it was mostly clouded during the first days of the conference, Mount Fuji was completely clear to view on the final day of the event.

The conference was well-attended by approximately 200 participants, including many students and younger researchers. The scientific program comprised four plenary lectures, fifteen invited lectures, one oral communication, and eighty-six posters. Many different aspects concerning antibiotics and other biological activities of natural products were discussed by the various speakers. The most common topics of their presentations were total synthesis of one or more natural products, new methodology and techniques for successfully screening natural product libraries for new structures and activities, and biological testing and evaluation of natural products for new applications or leads for SAR studies.

The conference began with a well-attended mixer on Tuesday evening that brought everyone together and successfully initiated many interactions and discussions among the attendees that continued throughout the conference. The scientific program began on Wednesday morning with a plenary lecture by Prof. Ōmura (Kitasato University) that summarized 'The Story of Avermectin and Ivermectin.' Following the initial rapid rise of ivermectin to 'Blockbuster' status in the animal health field, it is now also being used in the humanitarian efforts to eradicate the deadly and devastating parasitic diseases of onchocerciasis and lymphatic filariasis. ${ }^{1}$ A plenary lecture by Prof. Kuniaki Tatsuta (Waseda University) presented several examples from his more than one hundred total syntheses of natural products, including the big four antibiotic classes of macrolides, aminoglycosides, beta-lactams, and tetracyclines. ${ }^{2}$ In his plenary lecture, Prof. K Barry Sharpless (Scripps Research Institute) described some of his studies of comparative binding between first row and second row members of the periodic table, especially sulfur and fluorine and combinations of these two elements. The final plenary lecture was given by Prof. Amos B Smith III (University of Pennsylvania) who reported the very recent completion of the total synthesis of $(-)$-calyciphylline N. ${ }^{3}$

The first invited lecture of the conference was given by Dr. Peter Hammann (Sanofi Deutschland $\mathrm{GmbH}$ ) who surveyed the antibiotic R\&D pipeline and compared the list of antibiotics under development with medical needs. Unfortunately, he reported that very few novel antibiotic classes are being developed and that few antibiotics in development exhibit useful activity for treating the medically important resistant strains and/or Gram-negative bacteria. Other lectures examined new screening methods that might promote the discovery of new compounds and enhance the potential of natural products to open new research directions. Prof. Kazuo Shin-ya (National Institute of Advanced Industrial Science and Technology) described their efforts to use microbial genetics and biosynthesis to develop innovative methods to discover new natural products. These methods can then be applied to screen their library of $300000+$ samples of natural products (the world's largest such library).,5 Prof. Hideaki Kakeya (Kyoto University) discussed the discovery and use of bioactive natural products to initiate research in chemical biology. ${ }^{6}$ Prof. Masami Ishibashi (Chiba University) presented his results in finding and studying new compounds that would target and disrupt mechanisms of microbial communication and signaling. ${ }^{7}$ Prof. Shigeki Matsunaga (University of Tokyo) reported the isolation and structure determination of new metabolites that were isolated from marine sponges, a group which are currently one of the more prolific sources of new natural products. ${ }^{8}$ Prof. Gary Sulikowski (Vanderbilt University) outlined the multi-disciplined approach that they are employing to study natural products and to discover new and useful applications of these molecules. ${ }^{9}$ Prof. Yitzhak Tor (University of California at San Diego) focused on examining the details of binding within the ribosome by protein synthesis inhibitors and how these mechanistic details could be used to guide the design of new and more potent antibiotics. ${ }^{10}$ 
Biological activities other than antimicrobial were highlighted in some other lectures, especially anti-cancer activities, some of which were mentioned above. Dr Katsuya Tagami (Eisai) described the efforts that have been undertaken in process development for the commercial manufacturing of Eribulin mesylate (E7389, Halaven). This macrocyclic ketone analog of halichondrin B represents the first single agent to show a rate of overall survival from metastatic breast cancer in certain patients. ${ }^{11}$ In the lecture by Prof. Hirokazu Kawagishi (Shizuoka University), a plant growth stimulator formed by a fungus was shown to be the cause of the mysterious so-called fairy rings found in circular stimulated growth patterns. ${ }^{12} \mathrm{~A}$ new semi-synthetic insecticidal derivative currently under development named afidopyropen was the subject of a presentation by Dr. Kimihiko Goto (Meiji Seika Pharma). ${ }^{13}$

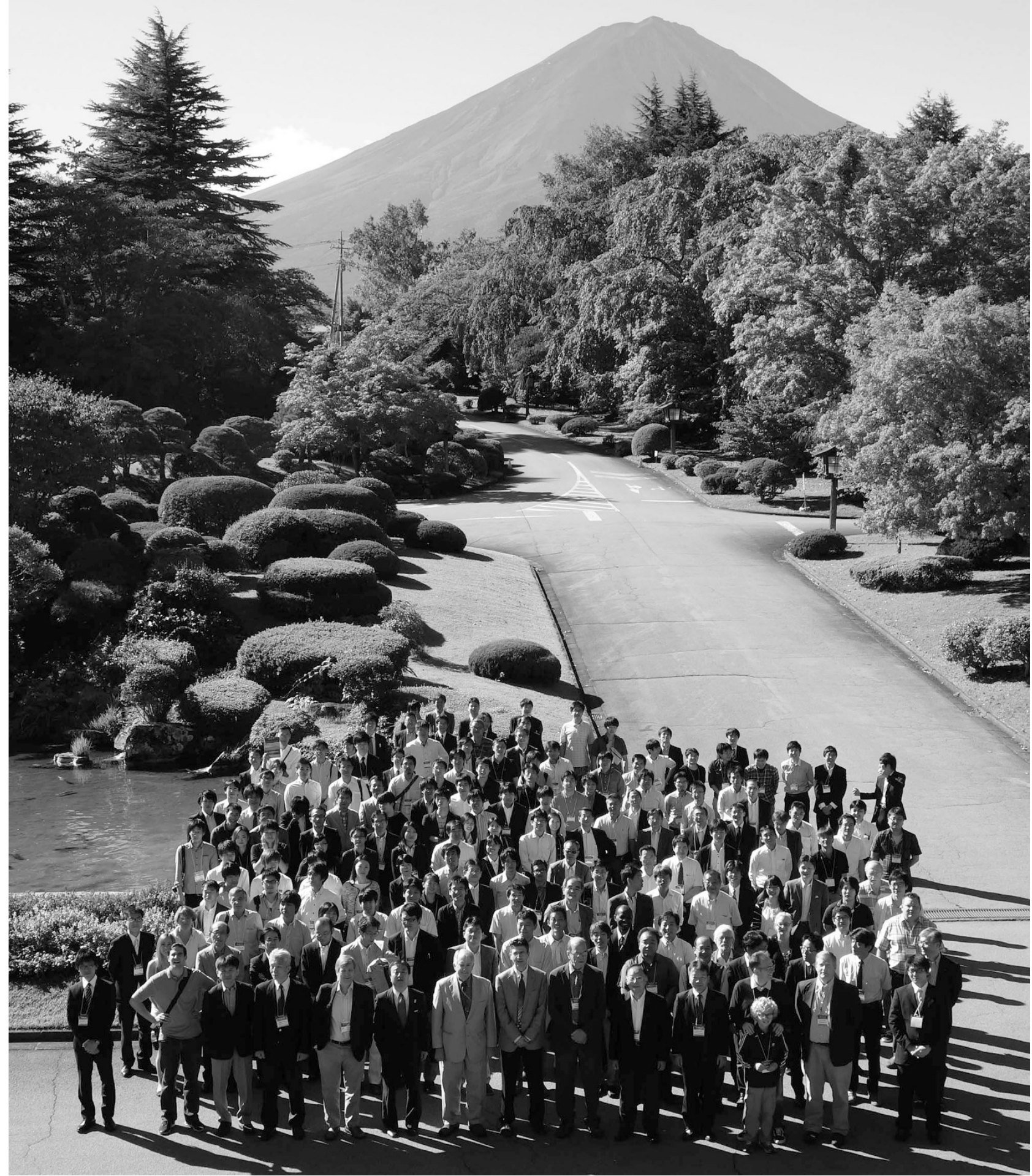

Group photograph and Mount Fuji from front of Fuji-View Hotel. 


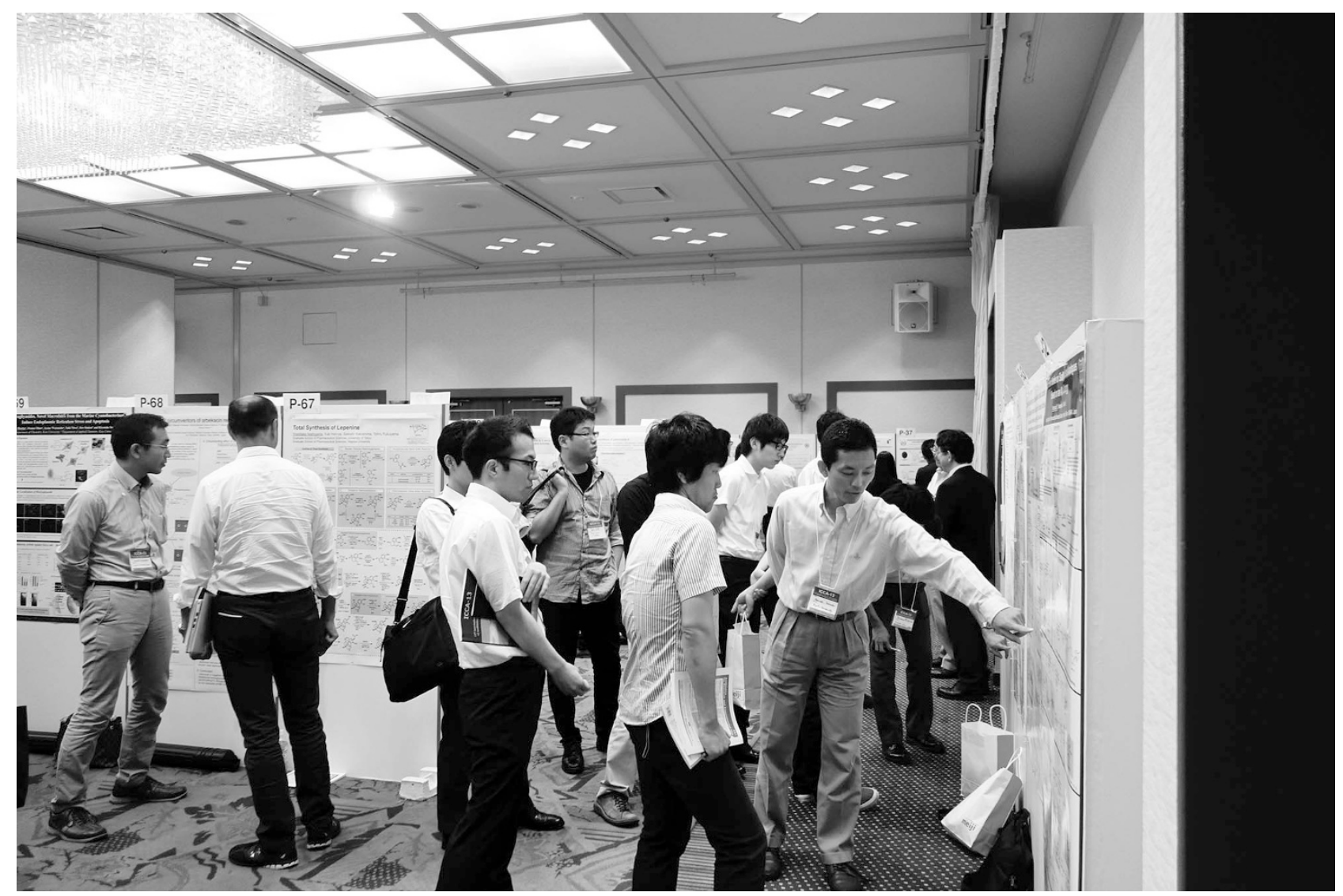

Synthesis of complex natural products was another significant topic that was part of several lectures. John Wood (Baylor University) reported his studies on the synthesis of phomoidride and citrinadin. ${ }^{14}$ Prof. Marek Chmielewski (Polish Academy of Sciences) described his on-going synthetic work with beta-lactam antibiotics and the use of the Kinugasa reaction to assemble new structures for examination in SAR studies. ${ }^{15}$ Prof. Hidetoshi Tokuyama (Tohoku University) described their completion of the total synthesis of $(-)$-acetylaranotin. ${ }^{16}$ Prof. Brian Stoltz (California Institute of Technology) described his synthetic methods for isoquinoline formation and the development of new aryne annulation methods. ${ }^{17}$ Prof. Noritaka Chida (Keio University) presented his approaches to the well-known anti-cancer natural product, taxol. The one short oral communication by Prof. Bartlomiej Furman (Polish Academy of Sciences) described a short concise synthesis of the cholesterol lowering agent, ezetimibe, starting with a 1,3-dipolar cyclo-addition to an appropriate nitrone. ${ }^{18}$

The two back-to-back poster sessions on the first day were filled with enthusiastic explanations and energetic discussions throughout the poster rooms about natural products and their biological activities. These two well-attended poster sessions were extremely successful and popular with the attendees. Several additional opportunities for discussion occurred during the various meal periods and venues in which all of the attendees were served as either a group or a buffet.

Finally, Prof. John Wood announced that he and colleagues in Texas will organize ICCA-14 in 2015. Further details concerning the exact site and date will be announced when they are available.

\section{ACKNOWLEDGEMENTS}

The conference is appreciative and grateful for the extremely generous support it has received from numerous sponsors, partners, and contributors who made all parts of this event so successful and enjoyable. I also thank Prof. Sunazuka for carefully reviewing this report.

1 Crump, A., Morel, C. M. \& Ōmura, S. The onchocerciasis chronicle: from the beginning to the end? Trends Parasitol. 28, 280-288 (2012).

2 Tatsuta, K. Total synthesis of the big four antibiotics and related antibiotics. J. Antibiot. 66, 107-129 (2013)

3 Yahata, H., Kubota, T. \& Kobayashi, J. Calyciphyllines N-P, alkaloids from Daphniphyllum calycinum. J. Nat. Prod. 72, 148-151 (2009).

4 Ikeda, H., Shin-ya, K. \& Ōmura, S. Genome mining of the Streptomyces avermitilis genome and development of genome-minimized hosts for heterologous expression of biosynthetic gene clusters. J. Ind. Microbiol. Biotechnol. (e-pub ahead of print 29 August 2013; doi:10.1007/s10295-013-1327-x).

5 Komatsu, M. et al. Engineered Streptomyces avermitilis host for heterologous expression of biosynthetic gene cluster for secondary metabolites. ACS Synth. Biol. 2, 384-396 (2013).

6 Otsuki, S. et al. Chemical tagging of a drug target using 5-sulfonyl tetrazole. Bioorg. Med. Chem. Lett. 23, 1608-1611 (2013).

7 Abdelfattah, M. S., Toume, K. \& Ishibashi, M. Yoropyrazone, a new naphthopyridazone alkaloid isolated from Streptomyces sp. IFM 11307 and evaluation of its TRAIL resistance-overcoming activity. J. Antibiot. 65, 245-248 (2012).

8 Takada, K. et al. Surugamides A-E, cyclic octapeptides with four D-amino acid residues, from a marine Streptomyces sp. J. Org. Chem. 78, 6746-6750 (2013).

$9 \mathrm{Du}, \mathrm{Y}$. et al. Biosynthesis of the apoptolidins in Nocardiopsis sp. FU 40. Tetrahedron 67, 6568-6575 (2011).

10 McCoy, L. S., Xie, Y. \& Tor, Y. Antibiotics that target protein synthesis. Wiley Interdiscip. Rev. RNA 2, 209-232 (2011).

11 Austad, B. C. et al. Commercial manufacture of Halaven $n^{\mathbb{R}}$ : Chemoselective transformations en route to structurally complex macrocyclic ketones. Synlett. 24, 333-337 (2013).

12 Choi, J. H. et al. Plant-growth regulator, imidazole-4-carboxamide, produced by the fairy ring forming fungus Lepista sordida. J. Agric. Food Chem. 58, 9956-9959 (2010). 
13 Ōmura, S., Tomoda, H., Kim, Y. K. \& Nishida, H. Pyripyropenes, highly potent inhibitors of acyl-CoA: cholesterol acyltransferase produced by Aspergillus fumigatus. J. Antibiot. 46, 1168-1169 (1993).

14 Murphy, G. K. et al. Toward the synthesis of phomoidride D. J. Org. Chem. 78, 477-489 (2013).

15 Mames, A. et al. Direct, catalytic synthesis of carbapenams via cycloaddition rearrangement cascade reaction: unexpected acetylenes' structure effect. J. Org. Chem. 75, 7580-7587 (2010).
16 Fujiwara, H., Kurogi, T., Okaya, S., Okano, K. \& Tokuyama, H. Total synthesis of (-)-acetylaranotin. Angew. Chem. Int. Ed. 51, 13062-13065 (2012).

17 Allan, K. M. \& Stoltz, B. M. A concise total synthesis of (-)quinocarcin via aryne annulation. J. Am. Chem. Soc. 130, 17270-17271 (2008).

18 Sniezek, M., Stecko, S., Panfil, I., Furman, B. \& Chmielewski, M. Total synthesis of ezetimibe, a cholesterol absorption inhibitor. J. Org. Chem. 78, 7048-7057 (2013) 